\title{
Recommended Design and Direction of Development for Humanoid Nursing Robots Perspective from Nursing Researchers
}

\author{
Tetsuya Tanioka, Kyoko Osaka, Rozzano Locsin, Yuko Yasuhara, Hirokazu Ito \\ Department of Nursing, Institute of Biomedical Sciences, Tokushima University, Tokushima, Japan \\ Email: tanioka.tetsuya@tokushima-u.ac.jp
}

How to cite this paper: Tanioka, T., Osaka, K., Locsin, R., Yasuhara, Y. and Ito, H. (2017) Recommended Design and Direction of Development for Humanoid Nursing Robots Perspective from Nursing Researchers. Intelligent Control and Automation, 8, 96-110.

http://dx.doi.org/10.4236/ica.2017.82008

Received: March 2, 2017

Accepted: May 23, 2017

Published: May 26, 2017

Copyright $\odot 2017$ by authors and Scientific Research Publishing Inc. This work is licensed under the Creative Commons Attribution International License (CC BY 4.0).

http://creativecommons.org/licenses/by/4.0/

cC) $\underset{\mathrm{BY}}{(7)}$ Open Access

\begin{abstract}
The purpose of this article is to describe recommendations towards the design and direction of development for Humanoid Nursing Robots (HNRs) from the standpoint of researchers of nursing care practice. Efforts to introduce robot technologies in nursing practice and to use them in elderly and high-tech healthcare environments have begun in developed countries like Japan. Companies are developing various types of robots, although their types and functionalities continue to require a clear identification and definition. Regardless, robot developments for health care purposes are progressing well to meet universal technological demands. While human caring has been a human-to-human relationship, in a nonhuman-to-human relationship in the case of HNRs, it is essential to consider ethical concerns and human safety. If HNRs are to support patients directly, they must be required to have the same level of comprehensive judgment ability and responsiveness as that of human nurses. This includes abilities to genuinely observe, judge, rapidly respond, and conduct human caring practice emphasizing individuality. If HNRs support patients independently, abilities which are much like those of humans will be required of them in addition to the appropriate intelligence and skillfulness to do so. A low level robot nurse exerts work that should be called non-nursing or as a medical aid assistant no matter who thinks and what these technologies can do. Similarly, a higher level HNR with higher level artificial intelligence is expected to exceed the capabilities of human beings. As such, current discourse and debate also include the concern that HNRs may now become one's superior or rather that the HNR is a subordinate thereby requiring human management.
\end{abstract}

\section{Keywords}

Autonomous Robots, Healthcare Robots (HRs), Humanoid Nurse Robots (HNRs), Nursing, Caring 


\section{Introduction}

The aging population in Japan has increased and is increasing at a phenomenal rate that is unequaled in any other country [1]. This, and the declining birth rate associated with the aging society have caused an aging population demographic structure [2]. Moreover, along with societal changes such as the increase in unmarried people and single-person households or separated parent-child households, the number of elderly persons living alone has also increased [3]. Similarly, many high-income countries in Asia like Japan, in Europe, and in North America are facing a demographic "double whammy", i.e., with the aging population, they also have an aging nursing workforce who are caring for the increasing numbers of elderly persons [4] [5]. In Japan, shortages of human resources in nursing practice are getting worse [6] [7].

Japan is also promoting the employment of human resources from other countries. Based on the EPA (Economic Partnership Agreement), Japan has started to accept Indonesian, Filipino, and Vietnamese practitioners in nursing since 2008 [8]. However, there is also the Japanese language barrier, and current policies regulating this emphasis are not progressing well, to the disadvantage of foreign practitioners. These problems/issues continue to influence the consideration of whether or not Japanese healthcare systems can continuously be aided with a limited nursing care staff. Therefore, it is important to effectively utilize limited human resources wisely, while firmly considering how to secure human health and human resources.

The authors as nursing researchers have investigated the issues and concerns about nursing robots. The purpose of this article is to describe the disciplinary recommendations of designing and developing Humanoid Nursing Robots (HNRs) from the standpoint of researchers of nursing.

\section{Considerations for Nursing Robots as Recommended by Nurse Researchers}

\subsection{Definition of Types of Humanoid Nursing Robots}

(1) Autonomous robots [9] are intelligent machines capable of performing tasks in the world by themselves, without explicit human control. Examples range from autonomous helicopters to Roomba ${ }^{\oplus}$, the robot vacuum cleaner.

(2) Healthcare robots (HRs) [10] are these robot used in the healthcare setting. A Healthcare robot can be used for healthcare setting, but it does not retain the adequate competency of "caring in nursing" like a human nurse.

(3) Humanoid nursing robots (HNRs) assumes them to be a fully functional robotic nurse who can do the same job as a human nurse as addressed in the next section on true and genuine nursing care for human beings.

\subsection{True and Genuine Nursing Care for Human Beings}

Two theoretical perspectives underpin the structuring of the recommendations towards the design and development of HNRs. These theories of Nursing pro- 
vide the essential elements, characteristic ingredients, and attributes of HNRs considering the discipline and practice of nursing that is described within the founded expectation of performance levels of nursing care.

Watson $(2010,2012)$ [11] [12] defines nursing as "a human science of persons and human health-illness experiences that are mediated by professional, personal, scientific, esthetic and ethical human transactions." Watson's theoretical underpinnings have seven assumptions: Caring can be effectively demonstrated and practiced only interpersonally. Caring consists of caritas factors that result in the satisfaction of certain human needs. Effective caring promotes health and individual or family growth. Caring responses accept the patient as he or she is now, as well as what he or she may become. A caring environment is one that offers the development of potential while allowing the patient to choose the best action for him or herself at a given point in time.

In contrast, Locsin (2005) [13] acknowledges the practice process of nursing as "knowing persons as caring". When nurses care for patients, nurses strive to understand the patient as a whole person. Within this theory, technology is used to continuously apprehend and express persons as caring who are ever-changing and unpredictable. Nursing is a knowledgeable practice provided within a human-to-human relationship in which caring is expressed in a continuous process. In order to understand persons, it is essential to enter into their world, recognize, understand, and appreciate who and what they are as whole persons. It is therefore necessary for high quality nursing practice that nurses are trusted by their patients and for patients to be empathically understood as human beings in a technology-dependent world of healthcare.

When "knowledge, judgment power, technical ability, and caring competence" are required in a particular situation, the nurse should be able to demonstrate "technological competency as caring in nursing." In demonstrating this competency, the nurse is envisioned to practice nursing using the process of knowing persons, in which technological knowing, mutual designing, and participative engaging [14] are the shared events. For example, in a critical situation, competent nurses can observe patients who may be suffering from severe headache, and who cannot sit and stand. The technologically competent nurse enters the patients' world of suffering and can be quick to assist such patients. On the contrary, a nurse who cannot distinguish patients' condition is unable to know the person fully in the moment, thereby fail to address the patient situation. As such, these nurses incompetent at that moment. The patient in the critical situation is seeking support and affirmation from nurses and other health care personnel; therefore, if the nurse does not notice the call (silent cry) for nursing, this nurse has failed to affirm the wholeness of the patient. Such a behavioral illustration is much like that of an office worker whose education is not of professional nursing. If and when the nurse does not understand and empathize (sympathy makes the nurse the authority of the pain instead of the patient who is experiencing the pain) with the patient's pain, and simply measures the blood pressure/body temperature and perhaps only listen to the patient's condition, 
such tasks can be possibly performed by reception computers as early as when the patient is first encountered.

It is but clear that what the patient is seeking is a nurse who expresses technological competency as caring, who will know him/her as person with hopes, dreams, and aspirations to be who he is, and wants to be [15] and be affirmed, supported, and celebrated as being a person. Nevertheless, the expression of true and genuine nursing is always changing as persons also continuously change.

\subsection{Caring in Nursing}

Caring represents an essential human need and is the fundamental constituent of professional nursing practice.

Mayeroff (1977) [16] in his book "On Caring", recognized and described eight ingredients that comprised "caring", namely, knowing, alternating rhythms, trust, hope, courage, honesty, patience, and humility. Likewise, Roach (1987) [17] has determined six attributes of caring, namely, compassion, competence, commitment, conscience, confidence and comportment which comprise the viewpoint of persons as caring. These ingredients and attributes constitute the characteristics of a caring person guided by Boykin and Schoenhofer's (2001) [15] theory of "Nursing as Caring." Nursing practice is described as the shared lived experience of the caring between the nurse and the person being nursed. In the process of caring, nurses develop and understand the knowledge and skill in caring constituting the knowledge base of nursing [18].

A deeper appreciation and understanding of caring and its expressions in nursing helps nurses understand other persons thereby influencing how they provide high-quality care [19]. The act of nursing is an excellent intervention performed by highly competent nurses, in which advanced observational abilities for patient situations, e.g. those with dementia, and intentional communication skills for patients are necessary.

It is difficult to determine and rationalize whether or not it was the prevailing culture of the day that implicitly prioritized technology and cure over caring and non-technological interventions that made nurses feel undervalued and virtually invisible within the decision making process in most health care facilities [20]. Health and health-related actions do not occur in isolation but are related to one another in time, space, and content [21]. Nurse caring was reported as an "interactive process that occurs during moments of shared vulnerability between nurse and patient" [22]. Processes of nursing practice [23] comprise the activities of caring, these include nurse attributes for professional caring (structure) which can be viewed as nurse interventions, and the dual nature of caring which encompasses attitudes and actions (process).

The dimension of interest is the opposite in that empathic capacities that robotics and artificial intelligence (AI) can demonstrate for humans can exist through programmed activities. Regardless, the knowledge generated will bring information to engage in relationships between empathy and AI and contribute to understanding its usefulness and impacting nursing/caring theories [24]. 
When the HNRs are able to express themselves through emotive behaviors much like humans can they will be able to convey empathic understanding [25] in which the benefactor will be the patient.

Figure 1 describes the expected relationships between and among nurses, HNR, and patients. The ability of HNRs to recall/respond to critical situations in patient care management is crucial. In situations such as these, it is important to share the experiences of patients. The functionality of HNRs to process language and maintain a conversation and to read and convey emotions are integral to the success of HNR relationships with and among nurses and patients.

\section{HNRs and Their Future Development}

\subsection{Evolutionary Process from HRs to HNRs}

Hubert Dreyfus and Stuart Dreyfus' work [26] was extremely influential in Benner's theory development. Adapting this model to nursing, Benner outlined the development of skill and learning in clinical nursing practice in her theory "Novice to Expert" [27]. Dreyfus and Dreyfus's novice to expert model can be found in Hubert Dreyfus's book What Computers Can't Do [26], first published in 1972. Hubert Dreyfus was a professor of philosophy who argued that the so-called AI displayed by computers was, in fact, nothing of the kind. Computers, he argued, can be programmed to make logical decisions based on an extremely rapid analysis of huge amounts of information, but can never be programmed to be intuitive or even to display common sense.

Benner [28] [29] detailed the acquisition of nursing expertise and proposed five possible expertise levels: novice, advanced beginner, competent, proficient, and expert. Nurses at the novice stage are still in nursing school. Especially, competent nurses are task-oriented and deliberately structure their work in terms of plans for goal achievement. Proficient nurses perceive situations as a whole and have more ability to recognize and respond to changing circumstances.

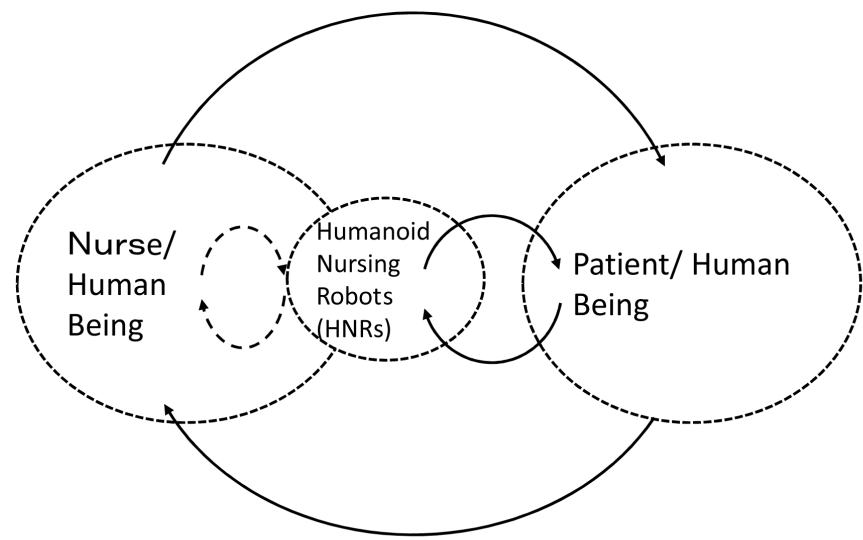

Humanoid nursing robots ability to remember which is critical in order to share the patient's experiences; the ability to process language and maintain a conversation; and to read and illustrate emotions.

Figure 1. The relationships between and among nurses, HNRs, and patients. 
Experts have an intuitive grasp of whole situations and are able to accurately diagnose and respond without wasteful consideration of ineffective possibilities. Thus, it may be useful to develop AI like the growth and development of human nurses.

Current development of $\mathrm{AI}$ is addressing issues of creating AIs to be more intelligent than humans [30], and ensuring that they use their advanced intelligence for good rather than ill effects. Due to the exponential evolution of future AI, the relationship between human beings and machines can profoundly change rapidly. There is that possibility that AI can actively learn.

Several studies exist that currently provide information on the topic of HRs' functionalities [25] [31] [32] [33] [34] [35]. Findings of these studies direct the perfection of "real" HRs in the future, those that can assist with the demands of human caring in nursing.

HRs that can perform simple tasks like taking vital signs or perform precise delivery [36], for example medications are critically needed. Reducing these types of human-dependent activities will provide human nurses the more important focus on direct human caring relationships and nursing care for these patients. Furthermore, HRs research [37] is urgently needed to focus on developing new computational algorithms for determining accurate patient emotional state classification in interactions between human and intelligent machine relations with HRs during health care services.

Any HNRs design to "replace" or enhance the work of the nurse and increase patient satisfaction must be cognizant of this relationality [38]. In this way, it behoove researchers of Computer science, Robotics, and Engineering to muster and obtain increased appreciation of the value of nursing care practices in health care, realize hints from the information and recommendations provided, and be able to design and create a new robot technology to support nursing practice. Therefore, in order to make the humanoid robot perform nursing, it requires advanced performance of real time nursing and the ideal HNRs need to have self-aware ability.

In order for HRs to interact with older people through a spoken dialogue, a high performance speech recognition system for speech recognition of elderly people is needed. It is necessary to develop the new speech data corpus to improve speech recognition accuracy of the speech of older people. This is particularly critical as interaction with such robots is expected to help among other aspects, the maintenance of the cognitive abilities of nursing home residents, while also providing them with companionship [39].

Figure 2 illustrates the relationship expected of HNRs, e.g. among the elderly, regarding its performance as based on its type and levels of function. Requisite nurse-robot activities are especially anticipated in assessing patients who need care and the characteristic performance of HNRs within the human-robot "caring" relationship. This is often expressed in the human-robot interface that is critical to expressions human caring that ought to be much like those conveyed by human nurses. 


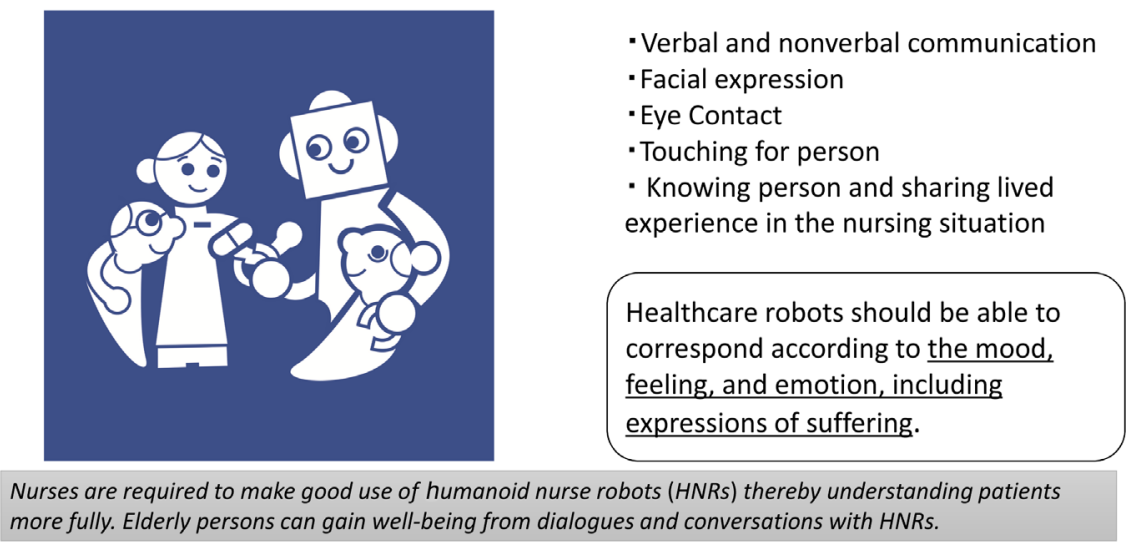

Figure 2. Performance of HNRs in transactive relationship.

\subsection{Theory-Based Nursing and HRs}

The increasing population of older persons world-wide fosters the recognition and increasing realization of the need of a theory-based practice model that can guide professional nursing practice in situations in which HRs are engaged with human persons (patients). Being critical participants (patients) in the process of human health care, transactive engagements of persons with HRs has become increasingly possible to envision, in the next few decades. A theory-guided nursing practice is integral to meeting the demands of this vulnerable population. Attaining quality health particularly in situations in which human beings, robots, and patients are involved may be the common health care practice in the very near future.

The realization of human and intelligent machine transactions in human health care has been the impetus for the development of the Transactive Relationship Theory of Nursing (TRETON) [40]. As the demands and needs for quality health care rise, particularly in human-resource poor environments and among the older adult population, the utilization of human-machine process requirements are intensified, and the realities and consequences of transactive relationships have become integral to assuring quality human health care.

Nursing caring practices involving intelligent machines with highly sophisticated robotic technological functions such as interactive capabilities may be the best option for the care of patients with the increasingly demanding human care such as the older adult population. In this situation, the HNRs with AI will be programmed to appreciate the meanings of the lived experiences of persons. Therefore, within the Transactive Relationship Theory of Nursing (TRETON), a nursing encounter where all nursing occurs encompasses the process of nursing as technological engagement and mutual knowing.

\subsection{Types of HRs and HNRs}

Discovering and deliberating the situation about AI and anthropomorphic machines in nursing and health care, before these become ordinary is of great importance. Erikson \& Salzmann-Erikson [25] [41] have mentioned that it is highly 
likely that AI will be implemented in nursing robotics in various forms, both in medical and surgical robotic instruments, and also as different types of automatons/droids and humanoids.

The basic question about HRs and HNRs and its development is, "should the aim of nursing be focused on developing humanoid nurse robot transcending AI and surpassing human intelligence and physical function?"

One of the popular robot functions in nursing today focuses on functionalities of nurse robots-the so-called "nursebot." In this robotic assistants project [42], the goal of the robot software system was to equip robots with intelligence programming so that these can make ethicomoral decisions, for example, about what reminders to issue and when, and balancing potentially competing objectives such as: (i) ensure that the user is aware of activities she/he is expected to perform, (ii) increase the likelihood that she/he will perform at least the required activities (e.g. taking medicine), (iii) avoid annoying the user, and (iv) avoid making the user overly reliant on the system.

During the course of experiments conducted in an assisted living facility, the robot successfully demonstrated that it could autonomously provide reminders and guidance for elderly residents.

Figure 3 illustrates the expected functionalities of intelligent machines identified and described in four levels and the projected timeframe regarding its advancing functionalities (Please see Section 3.4).

\subsection{Levels of Function and Timeline of HRs and HNRs}

- Level 1: HRs in 2020, are low level "bots" that works much like a HNR does. This intelligent machine will do vital sign measurements: blood pressure, pulse measurement, percutaneous oxygen saturation measurement, clerking, and so on. It is this public image of the nurse particularly in hospital settings that provides a semblance of its ontological and epistemological work. Activities such as these can include bathing, assisting with meals, taking vital signs, making beds, assisting physicians etc.

Should we aim to develop the HNRs transcendence to the moment when Al surpasses human intelligence and physical function?

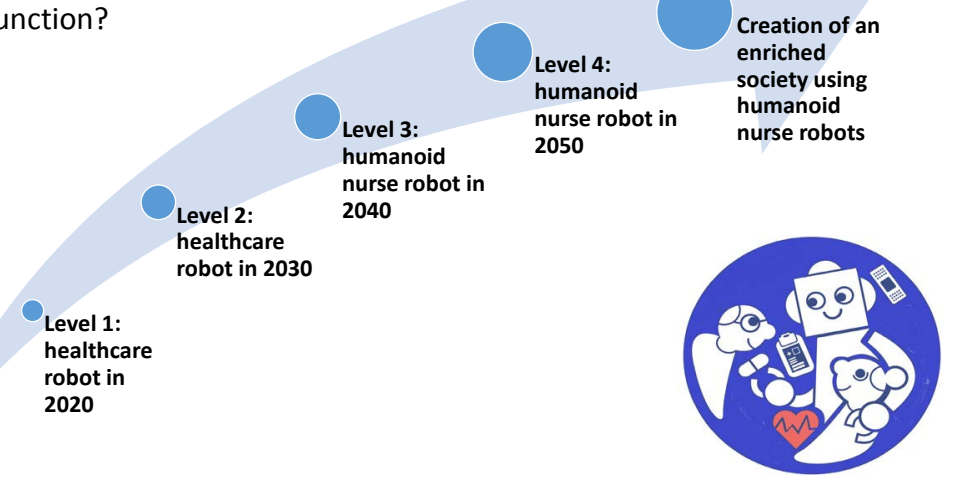

Figure 3. HRs, HNRs and its future development. 
- Level 2: HRs in 2030. This type of robot can manage and perform moderate level of work. HNR is a robot with interpersonal communication, in addition to the expected work of low level nurses, can understand, empathize, and share empathy with patients and families. This level of robot nurse can also interact with other professionals. It may seem inconceivable that this so called "excellent nursing" practice is the outcome of competency of practice in human engagement involving physico-physiological and interactive relations with and among other persons as patients. If we are to make the nurse robot's heart/mind necessary for nursing equipped with AI, it needs the ability to first observe patient's need, correctly evaluate it, and communicate its findings to the patient in appropriate words. Also nurse robots communicate their empathy with technological competence. For example, a series of actions that integrate not only words but also "knowledge, judgment, technical skills, and care" are expected of these nursing robots.

- Level 3: HNRs in 2040, will be equipped and expected to perform high level of work as HNR assumes to be a fully functional robotic nurse who can do the same job as a human nurse. It is important to be reminded that all levels of robot nurses are equipped with terminals of electronic medical charts for easy access.

- Level 4: HNRs in 2050, by this time, transcendence becomes the feature of robot functionality. It refers to the occasion when AI exceeds human intelligence and physical functioning. Should we aim to develop the HNR towards transcendence?

Usually the singularity [43] a hypothetical moment in time when AI and other technologies have become so advanced that humanity undergoes a dramatic and irreversible change "maybe a hoped-for occasion."

Many definitions exist, but one that serves AI and humanity well is what Kurzweil [44] has described, that singularity [44] is a trait marking one as distinct from others; a peculiarity. Often, computers manage to illustrate a hypothetical future point in time when AI will surpass human intelligence and be able to self-replicate and improve itself autonomously. If it is something uncommon or unusual, it should be a HNR enriching human society.

While Singularity is a conditional "reality" for HNRs' existence, the question of machines potentially creating disorder to humanity cannot be simply ignored. Ito, et al. [45] has addressed this viewpoint studying concerns of present-day health care workers about practicing their professions with these HNRs. Importantly, we must not forget that HNR enriches human life. In other words, we should not create things that threaten our lives.

\section{Is the HNRs Really Necessary for Human Health Care?}

This technological development is envisioned to make human life convenient. However, for such a technology, the development for future human society also includes a sense of fear. Nurse researchers have been conducting research in cooperation with researchers and engineering companies focused on science and 
technology, and the humanities, particularly from the standpoint of nursing. For future development of a HNR with such AI, interdisciplinary collaborative team will need to include researchers focused on humanity studies such as philosophy, ethics, arts, and aesthetics, and not only on engineering and the technological sciences.

If we develop a HNR, we need to consider its necessity.

Contemporary health care and its providers and participants can have the opportunity to examine the many considerations of having HRs deliver activities tantamount to health care practice.

Will patients be able to accept the care of a $\mathrm{HR}$ as equivalent to nursing care practiced by a human nurse?

Will patients be able to recognize that the HR is a human nurse practicing nursing?

Will members of the healthcare team possibly accept the HNR as a legitimate team member?

If the HNR can demonstrate its technological competency as caring in nursing, what will make "its" performance different from what human nurses currently do?

In the current research situation there exists difficulties with HNRs development. First, current HNRs have low linguistic conversation skills. Secondly, there are several evaluation studies to determine the effectiveness of robot-human interactions, but the value of the second difficulty is really dependent on whether or not we can accurately evaluate human reactions.

If HNRs have poor interpersonal skills, humans will immediately lose interest in them. This is the same with human-to-human relations. Human beings are not interested in "unattractive persons." However, HNRs have the possibility of growing as though they are human beings.

As the direction of HNR development in the future, the ultimate question is asked, "Is the being of humanoid robots beyond human beings really necessary?" The ultimate answer is that its necessity is based on the current and future outlook of human health care to meet the demands of human health care and wellbeing.

Regarding data retrieval capabilities, some AIs have already exceeded the human ability. However, the ability of empathic understanding in interpersonal relationship has not been completely addressed yet. From the philosophical point of view, "What is being human," "What is a nurse," "What is nursing," "What is a humanoid," "What is a HNR," "Why is HNR necessary?" These questions propel the furtherance of potentialities of HNRs which are required and hopefully considered in the research and development of artificially intelligent robots.

On the other hand, since product development is considered on an economic basis, there is a possibility that developing products of HNR will be economically lucrative. As such, the motivation to design and develop HNRs will be beyond the consideration of humanity and humanness, and into the economic world. Since HNR is a technology for human beings, it is necessary to carefully proceed 
with its development. Important to consider as well is the aging of human society, with fewer children born to families in advanced countries, human beings as we know them today may eventually disappear or be challenged to change. Will the HNR as we know it today and envisioned for tomorrow be able to meet the demands of these technologies, serving the human population as we will know it at that time?

\section{Nursing and Robots in Elderly Care}

In Japan, efforts to introduce robot technologies in nursing practice and to use them in elderly and high-tech healthcare environments have begun. With robot introduction to hospitals, nursing care facilities and companies are positioning themselves to develop various types of robots. However, with limited understanding of professional nursing practice the types of robots and their functionalities remain problematic. This requires a clear identification and definition by no less than the researchers and scientists of nursing. Their engagements toward quality health remain critical aspects of excellent human health care. While robot development for health care is progressing well to meet these universal technological demands, nevertheless, it is critical that the developments of HNRs are centered on nursing researchers' recommendations.

For instance, some of the important aspects which are critical to caring for older persons with dementia include care practices for deficits in cognition and self-care [46], interventions to maintain activities of daily living (ADL) for maintaining physical strength and mobility, and improving quality of life (QOL). Likewise, these care practices ought to include interventions to decrease depressive symptoms and increase pleasant events to maintain cognitive functioning [47], and provide altruistic care which implies that nurses show attitudes such as cheerfulness, compassion and kindness, love, joy and peace in their caring [48], and spiritual care [49]. Altogether these qualities also support the development of crucial characteristics and functionalities of robots for quality elderly care.

Furthermore, the possibility that "rehabilitation support robots" can substitute the work of physical therapists and occupational therapists towards engaging patients for exercise and as a "humanoid walking trainer" [50] to help the overworked staff improve the physical and cognitive functioning of the elderly is another consideration. However, in nursing, not only does the practice involve physical ADL, but also the "intentional intervention" that is necessary to improve the QOL of the elderly. The most important attribute in nursing is the relationship expressed as caring between patients and nurses as an interactive engagement that gives meaning to living their own lives.

\section{Implications and Conclusions}

Staying abreast with developments regarding redefinitions of nursing and its underlying beliefs, values, and assumptions is relevant to understanding the implications of AI and HNRs in healthcare. Human caring has always been based 
on a human-to-human relationship. However, in a nonhuman-to-human relationship in the case of HNRs, it is essential to consider what is required of them in the aspects of ethical concerns and human safety. Also, if HNRs are to support patients directly, they will be required to have the same level of comprehensive judgment ability and responsiveness as that of human nurses and care staff does in their everyday life. This includes the abilities to deeply observe, judge, quickly respond, and conduct caring with an emphasis on individuality. If HNRs are to support patients independently, abilities close to those of humans will be required of them in addition to the appropriate knowledge and skills to do so.

A low level robot nurse (Level 1) exerts work that should be called non-nursing or as a medical aid assistant no matter who thinks and what these technologies can do. Similarly, a higher level (Levels 2 and 3) HNR with higher level AI is expected to exceed the capabilities of human beings. However, with a higher level of intelligence (Level 4), HNRs will exceed the capacity of human beings, and the argument that the robot nurse is now your superior or that the HNR is a subordinate will naturally take place.

When various nursing robots become common practice in institutional settings, they will have a major impact on nursing work, the nursing profession, and healthcare in general. Nursing robots will redefine ideas about nurses in general as well as ideas about nursing attributes and conceptual frameworks of comfort and safety in particular.

\section{Acknowledgements}

This work was supported in part by JSPS KAKENHI Grant Number JP24390477. We express our sincere thanks to Dr. Savina Schoenhofer, for her astute, magnanimous, collegial and collaborative annotations and recommendations in the development of this theoretical paper.

\section{References}

[1] Muramatsu, N. and Akiyama, H. (2011) Japan: Super-Aging Society Preparing for the Future. The Gerontologist, 51, 425-432. https://doi.org/10.1093/geront/gnr067

[2] Bongaarts, J. (2009) Human Population Growth and the Demographic Transition. Philosophical Transactions of the Royal Society of London, 364, 2985-2990. https://doi.org/10.1098/rstb.2009.0137

[3] Tsutsui, T. (2014) Implementation Process and Challenges for the CommunityBased Integrated Care System in Japan. International Journal of Integrated Care, 14, e002. https://doi.org/10.5334/ijic.988

[4] Nargund, G. (2009) Declining Birth Rate in Developed Countries: A Radical Policy Re-Think Is Required. Facts, Views \& Vision in ObGyn, 1, 191-193.

[5] Buchan, J. and Aiken, L. (2008) Solving Nursing Shortages: A Common Priority. Journal of Clinical Nursing, 17, 3262-3268. https://doi.org/10.1111/j.1365-2702.2008.02636.x

[6] Sawada, A. (1997) The Nurse Shortage Problem in Japan. Nursing Ethics, 4, 245252. https://doi.org/10.1177/096973309700400309

[7] Kimura, E., Ohnishi, M., Norihiko, T. and Ishihara, K. (2006) Development of Nursing Care System with Web Service. AMIA Annual Symposium Proceedings, 
2006, 984

[8] The Japan Foundation (2016) Japanese-Language Pre-training Program for Indonesian and Filipino Candidates for Nurses and Care Workers under Economic Partnership Agreements (EPA). https://www.jpf.go.jp/e/project/japanese/education/training/epa/

[9] Bekey, G.A. (2005) Autonomous Robots, From Biological Inspiration to Implementation and Control. MIT Press Books, Cambridge.

[10] Wynsberghe, A. (2015) Humano: Ethics, Design and Implementation (Emerging Technologies, Ethics and International Affairs). Routledge, New York.

[11] Watson Caring Science Institute (2010) Core Concepts of Jean Watson's Theory of Human Caring/Caring Science.

https://www.watsoncaringscience.org/files/Cohort\%206/watsons-theory-of-humancaring-core-concepts-and-evolution-to-caritas-processes-handout.pdf

[12] Nursing Research (2012) Nursing Theories: Jean Watson's Philosophy of Nursing. http://currentnursing.com/nursing_theory/Watson.html

[13] Locsin, R. (2005) Technological Competency as Caring in Nursing: A Model for Practice. Sigma Theta Tau International Honor Society of Nursing Press, Indianapolis.

[14] Locsin, R. (2016) Technological Competency as Caring in Nursing: Co-Creating Moments in Nursing Occurring Within the Universal Technological Domain. The Journal of Theory Construction and Testing, 20, 5-11.

[15] Boykin, A. and Schoenhofer, S. (2001) Nursing as Caring: A Model for Transforming Practice. Jones \& Bartlett Learning, Sudbury, MA.

[16] Mayeroff, M. (1971) On Caring. Harper \& Row, New York.

[17] Roach, S. (1987) The Human Act of Caring. Canadian Hospital Association, Ottawa, Canada.

[18] Cheung, J. (1998) Caring as the Ontological and Epistemological Foundations of Nursing: A View of Caring from the Perspectives of Australian Nurses. International Journal of Nursing Practice, 4, 225-233. https://doi.org/10.1046/j.1440-172X.1998.00101.x

[19] Patistea, E. (1999) Nurses' Perceptions of Caring as Documented in Theory and Research. Journal of Clinical Nursing, 8, 487-495. https://doi.org/10.1046/j.1365-2702.1999.00269.x

[20] Kitson, A. (2001) Nursing Leadership: Bringing Caring Back to the Future. Quality in Health Care, 10, ii79-ii84.

https://www.ncbi.nlm.nih.gov/pmc/articles/PMC1765753/pdf/v010p0ii79.pdf

[21] Beach, M.C., Inui, T. and the Relationship-Centered Care Research Network (2006) Relationship-Centered Care: A Constructive Reframing. Journal of General Internal Medicine, 21, S3-S8. https://doi.org/10.1111/j.1525-1497.2006.00302.x

[22] Wolf, Z.R., Giardino, E.R., Osborne, P.A. and Ambrose, M.S. (1994) Dimensions of Nurse Caring. Journal of Nursing Scholarship, 26, 107-112. https://doi.org/10.1111/j.1547-5069.1994.tb00927.x

[23] McCance, T.V. (2003) Caring in Nursing Practice: The Development of a Conceptual Framework. Research and Theory for Nursing Practice, 17, 101-116. https://doi.org/10.1891/rtnp.17.2.101.53174

[24] Erikson, H. and Salzmann-Erikson, M. (2016) Future Challenges of Robotics and Artificial Intelligence in Nursing: What Can We Learn from Monsters in Popular Culture? The Permanente Journal, 20, 15-243. https://doi.org/10.7812/tpp/15-243 
[25] Osaka, K., Tsuchiya, S., Ren, F. and Tanioka, T. (2008) Analysis of Empathetic Understanding Using Relationship between Electrode and Frequency. Proceeding of ICAI2008, Beijing, 116-121.

[26] Dreyfus, S.E. and Dreyfus, H.L. (1980) A Five-Stage Model of the Mental Activities Involved in Directed Skill Acquisition. Storming Media, Washington DC.

[27] Gardner, L. (2012) From Novice to Expert: Benner's Legacy for Nurse Education. Nurse Education Today, 32, 339-340. https://doi.org/10.1016/j.nedt.2011.11.011

[28] Benner, P. (1984) From Novice to Expert: Excellence and Power in Clinical Nursing Practice. Addison-Wesley Publishing Company, Menlo Park, CA.

[29] McHugh, M.D. and Lake, E.T. (2010) Understanding Clinical Expertise: Nurse Education, Experience, and the Hospital Context. Research in Nursing \& Health, 33, 276-287. https://doi.org/10.1002/nur.20388

[30] Bostrom, N. and Yudkowsky, E. (2014) The Ethics of Artificial Intelligence. In: Frankish, K. and Ramsey, W., Eds., Cambridge Handbook of Artificial Intelligence, Cambridge University Press, New York, 316-334.

https://intelligence.org/files/EthicsofAI.pdf

[31] Tanioka, T., Yasuhara, Y., Osaka, K., Ito, H., Kato, K., Sugimoto, H. and Locsin, R. (2015) Performance Requisites for Compassionate Nursing Robots, with Communication Competency. Proceeding of the 7 th International Conference on Information, Taipei, November 2015, 77-80.

[32] Osaka, K., Tanioka, T., Yasuhara, Y. and Locsin, R. (2016) Empathic Understanding in Human-Robot Communication: Influences on Caring in Nursing. GSTF Conference Proceedings on WNC2016, Singapore, July 2016, 233-239.

[33] Yasuhara, Y., Osaka, K., Tanioka, T. and Locsin, R. (2016) Artificiality in Intelligence of Human Caring Machines: Towards Its Effective Functioning in Human Patient Care Demands. GSTF Conference Proceedings on WNC 2016, Singapore, July 2016, 240-245.

[34] Tanioka, T. and Locsin, R. (2012) Feasibility of Developing Nursing Care Robots. Proceeding of 8 th International Conference on Natural Language Processing and Knowledge Engineering (NLP-KE12), China, September 2012, 567-570.

[35] Yasuhara, Y., Tamayama, C., Kikukawa, K., Osaka, K., Tanioka, T., Watanabe, N., Chiba, S., Miyoshi, M., Locsin, R., Ren, F., Fuji, S., Ogasawara, H. and Mifune, K. (2012) Required Function of the Caring Robot with Dialogue Ability for Patients with Dementia. AIA International Advanced Information Institute, 4, 31-42.

[36] Huang, S., Tanioka, T., Locsin, R., Parker, M. and Masory, O. (2011) Functions of a Caring Robot in Nursing. Proceeding of 7 th International Conference on Natural Language Processing and Knowledge Engineering (NLP-KE), Tokushima, 27-29 November 2011, 425-429. https://doi.org/10.1109/nlpke.2011.6138237

[37] Swangnetr, M., David, B. and Kaber, D. (2013) Emotional State Classification in Patient-Robot Interaction Using Wavelet Analysis and Statistics-Based Feature Selection. IEEE Transactions on Human-Machine Systems, 43, 63-75. https://doi.org/10.1109/TSMCA.2012.2210408

[38] Locsin, R., Tanioka, T. and Kawanishi, C. (2005) Anthropomorphic Machines and the Practice of Nursing: Knowing Persons as Whole in the Moment. Proceedings of 2005 IEEE International Conference on Natural Language Processing and Knowledge Engineering, Wuhan, 30 October-1 November 2005, 825-829. https://doi.org/10.1109/NLPKE.2005.1598850

[39] Iribe, Y., Kitaoka, N. and Segawa, S. (2015) Development of New Speech Corpus for Elderly Japanese Speech Recognition. 2015 International Conference Oriental COC 
OSDA Held Jointly with 2015 Conference on Asian Spoken Language Research and Evaluation (O-COCOSDA/CASLRE), Shanghai, 28-30 October 2015, 27-31.

[40] Tanioka, T. (2017) The Development of the Transactive Relationship Theory of Nursing (TRETON): A Nursing Engagement Model for Persons and Humanoid Nursing Robots. International Journal of Nursing and Clinical Practices, 4, 223.

[41] Tanioka, T., Yasuhara, Y., Osaka, K., Ito, H. and Locsin, R. (2017) Supervising Editor: Nursing Robots: Robotic Technology and Human Caring for the Elderly, Fukuro Shuppan Publishing, Okayama, Japan.

[42] Pineau, J., Montemerlo, M., Pollack, M., Roy, N. and Thrun, S. (2003) Towards Robotic Assistants in Nursing Homes: Challenges and Results. Robotics and Autonomous Systems, 42, 271-281.

[43] Oxford Living Dictionaries (2017) Singularity. https://en.oxforddictionaries.com/definition/singularity

[44] American Heritage Dictionaries (2013) The American Heritage ${ }^{\star}$ Dictionary of the English Language. 5th Edition, Houghton Mifflin Harcourt Publishing Company, Boston.

[45] Ito, H., Miyagawa, M., Kuwamura, Y., Yasuhara, Y., Tanioka, T. and Locsin, R. (2015) Professional Nurses' Attitudes towards the Introduction of Humanoid Nursing Robots (HNRs) in Health Care Settings. Journal of Nursing and Health Sciences, 9, 73-81.

[46] Desai, A.K. and Grossberg, G.T. (2001) Recognition and Management of Behavioral Disturbances in Dementia. The Primary Care Companion to The Journal of Clinical Psychiatry, 3, 93-109. https://doi.org/10.4088/PCC.v03n0301

[47] Logsdon, R.G., McCurry, S.M. and Teri, L. (2007) Evidence-Based Interventions to Improve Quality of Life for Individuals with Dementia. Alzheimer's Care Today, 8 , 309-318.

[48] Sawatzky, R. and Pesut, B. (2005) Attributes of Spiritual Care in Nursing Practice. Journal of Holistic Nursing, 23, 19-33. https://doi.org/10.1177/0898010104272010

[49] Ødbehr, L.S., Kvigne, K., Hauge, S. and Danbolt, L.J. (2015) Spiritual Care to Persons with Dementia in Nursing Homes: A Qualitative Study of Nurses and Care Workers Experiences. BMC Nursing, 14, 70. https://doi.org/10.1186/s12912-015-0122-6

[50] Piezzo, C. and Suzuki, K. (2016) Design of an Accompanying Humanoid as a Walking Trainer for the Elderly. 201625 th IEEE International Symposium on Robot and Human Interactive Communication (RO-MAN), New York, 26-31 August 2016, 467-472. https://doi.org/10.1109/ROMAN.2016.7745160 
Submit or recommend next manuscript to SCIRP and we will provide best service for you:

Accepting pre-submission inquiries through Email, Facebook, LinkedIn, Twitter, etc. A wide selection of journals (inclusive of 9 subjects, more than 200 journals)

Providing 24-hour high-quality service

User-friendly online submission system

Fair and swift peer-review system

Efficient typesetting and proofreading procedure

Display of the result of downloads and visits, as well as the number of cited articles Maximum dissemination of your research work

Submit your manuscript at: http://papersubmission.scirp.org/

Or contact ica@scirp.org 